high helium content of beryls might conceivably be due to $\mathrm{Be}^{8}$ which has existed in geological times even if not known to exist at present. This implies, however, that $\mathrm{Be}^{8}$ existed at least in Palæozoic times, a relatively very late period since the star state and proton bombardment. The recent experiments of Cockeroft and Walton ${ }^{5}$ would indicate that $\mathrm{Be}^{8}$ can have only a very short life period. A possible source of excess helium might be found, however, in the following proposed mechanism:

$\mathrm{R}^{9}+\alpha$-particle $=3$ He nuclei + neutron,

and treating this in a similar manner to Chadwick's treatment, ${ }^{6}$ the maximum energy of the emission of the neutron is about $5.2 \times 10^{6}$ electron volts as compared to $5 \cdot 7 \times 10^{8}$ found in Chadwick's experiments and a maximum energy of about $8 \times 10^{5}$ electron volts given by the equation assuming $\mathrm{C}^{12}$ is the end product. If both mechanisms are possible we might then expect two groups of neutrons of different maximum energies. In the Palæozoic beryl, atout $300 \times 10^{5}$ years old, radium was detected but no thorium. The $\alpha$-particle of greatest kinetic energy is therefore from $\mathrm{Ra} \mathrm{C}^{\prime}$ which would give a maximum energy to the neutron of about $7.7 \times 10^{6}$ volts or about $10.5 \times 10^{6}$ if $\mathrm{C}^{12}$ is the end product.

Even if every $\alpha$-particle is effective, however, a maximum of only three times the helium produced by the radioactive integration can be expected. The contribution to the helium which is to be expected from the work of N. Feather, ${ }^{7}$ in which it is shown possible to free an $\alpha$-particle by neutron bombard. ment of nitrogen or possibly some other element, contained in the mineral, can only be a small fraction of the radioactive helium, since only one neutron is formed from each effective $\alpha$-particle and but a small fraction of these cause disintegration. Moreover, the sequence of events by which a neutron ejects a proton in the mass of the beryl and this in turn builds $\mathrm{Be}^{8}$ which breaks down into two $\alpha$-particles is so unlikely as not to come into consideration at all in accounting for the excess helium.

All the above possible mechanisms are, therefore, insufficient to account for the excess helium in the beryls such as from Chester, Penn., U.S.A., containing $0.19 \times 10^{-2} \mathrm{gm}$. uranium which would generate approximately 0.065 c.c. of helium in $300 \times 10^{6}$ years, a reasonable lapse of time since the Palæozoic age, compared to the experimentally determined value of at least 0.68 c.c.

Nevertheless, such possible sources of extraneous helium must be considered when determining geological age by the helium ratio, especially when the lighter elements are in abundance.

Massachusetts Institute of Technology,

WM. D. URRY.

Cambridge, Mass. Oet. 8.

\footnotetext{
${ }^{3}$ Proc. Roy. Soc., A, 80, 572; 1908. A, 84, $194 ; 1910$.

2 Y. Phys. Chemie, B., 112, $170 ; 1928$.

3 NATURE, 128, 567; 1929

- NATURE, 123, 607; 1929 .

5 Proc. Roy. Soc., A, 136, 743; 1932

- Proc. Roy. Soc. A, 136, 699; 1932.

? Proc. Roy. Soc., A, 136, $709 ; 1932$.
}

\section{Natural Melody}

IN his letter in NATURE of November 5 on "Natural Melody" Sir Richard Paget inquires whether such an effect can have been produced in Nature, as, for example, by a broken bamboo stem. The following extract from Godinho de Eredia's "Report on the
Golden Chersonese" : 1597-1600 (English translation by Mr. J. V. Mills of the Malayan Civil Service) may be of interest, though it concerns speech, not melody :

"To conclude entirely with the Peninsula, I will relate a curious phenomenon which occurs at the mouth and entrance of the River Panagim [now called the River Linggi. J.B.S.]: here there are dense thickets of Bamboos, and among them are two very tall stout Bamboos which are set in such a manner that one of them towers over the other; now it is an actual fact that by day and by night human voices are heard proceeding from these Bamboos; one of them says ' $S u d a$ ', that is to say, 'Enough', and the other replies 'Bolon', which is as much as to say 'Not yet'.

"I always regarded this as a worthless fairy-tale, until Affonso Vicente, Ambassador to Achem, assured me that he personally heard these voices saying 'suda', 'bolon', when he went to this place on the Panagim for the sole purpose of observing this most curious occurrence in the year 1595."

\section{8, Chaucer Road, Bedford.} Nov, 6.

\section{An Epithelial Tumour of the Intestine of a Frog}

THe following report is made because a similar pathological condition has not previously come to my attention. The frog, Rana pipiens, was brought to the laboratory from the frog tanks with a number of others for the use of students. There was nothing in its external appearance to indicate any abnormality. It seemed as well nourished as any. When the abdomen was opened it was found to be nearly filled with an irregularly cubical mass, the liver was much compressed and only about two centimetres of intestine could be found. In colour the mass was pale yellowish brown; its consistency varied, some parts being quite firm to the touch and others cystic. On section, tubular openings coursing irregularly through the mass were disclosed, and where these were near the surface they gave the impression of a cyst when palpated. These tubes appeared to be the missing intestine. The entire specimen was submitted to the Department of Pathology, which reported as follows :

"Large yellowish tumour mass occupying main part of abdomen of frog, with a lumen suggesting intestine.

"Section shows tumour to be of epithelial origin; the cells are arranged in irregular acini suggesting a tumour arising from intestine.

"Epithelial tumour."

It is remarkable that the frog could have lived in spite of the interference with digestion and absorption that would seem inevitable from the presence of so large a mass in the abdomen, and especially of one involving the intestine to so great an extent. Inspection and handling of the voluntary muscles did not reveal any atrophy. I shall be much interested to hear from anyone who has observed a similar condition, and should like to secure all the information possible as to the frequency of occurrence, rate of growth, and effect on health and length of life.

ARDRey W. Downs.

Department of Physiology and Pharmacology, University of Alberta.

Oct. 21.

No. 3290, Vol. 130] 